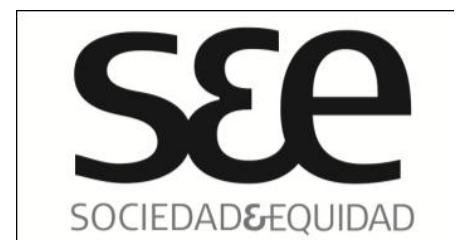

SOCIEDADEEQUIDAD

\section{Pobreza y jurisprudencia constitucional colombiana: El caso de los Recicladores}

\title{
Resumen
}

Este artículo estudia la interpretación constitucional sobre las medidas de política pública para la superación de la pobreza de un grupo tradicionalmente marginado: los recicladores. La metodología utilizada es la construcción de línea jurisprudencial, a partir de la cual se identifican los principales argumentos usados por la Corte Constitucional para resolver estos casos y son discutidos posteriormente a partir de los aportes teóricos del profesor Pogge, en torno a su interpretación institucional de los Derechos Humanos. Finalmente, en este artículo se concluye que la configuración de nuevos procedimientos institucionales y administrativos que consoliden un modelo institucional-gubernamental más inclusivo y participativo, específicamente de los grupos en condiciones de desventaja social y económica, es un cambio estructural inaplazable y significativo para avanzar hacia la superación de la pobreza.

\section{Palabras Claves}

Recicladores, Corte Constitucional, Acción afirmativa, Empresarios, Igualdad sustantiva, Discriminación.

\footnotetext{
${ }^{1}$ La autora es Abogada, Magíster en Política Social, investigadora del Grupo de Filosofía Moral y Política del Instituto Pensar de la Pontificia Universidad Javeriana y docente del Instituto de Bioética de la misma Universidad. Es además consultora de la Defensoría del Pueblo delegada para las Políticas Públicas en Colombia. Sus líneas de investigación son: Derechos Humanos y Políticas Públicas, bienes comunes en América Latina, bioética y derecho.
} 


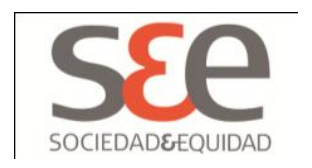

\begin{abstract}
This paper studies the constitutional interpretation of public policy measures to overcome poverty in a traditionally marginalized group: the recyclers. The employed methodology is the construction of a new case-law line, identifying the main arguments used by the Constitutional Court to resolve them, and then discussing those arguments departing from the theoretical contributions of Professor Thomas Pogge, specifically from his Institutional interpretation of Human Rights. Finally, this paper concludes that the configuration of new administrative and institutional procedures for the consolidation of a new, more inclusive and participatory institutional-governmental model, specifically for the economically disadvantaged groups, is a significant structural change that cannot be postponed if we wish to progress towards overcoming poverty.
\end{abstract}

\title{
Keywords
}

Recyclers, Constitutional Court, Affirmative action, Business, Substantive equality, Discrimination.

\section{Introducción}

La Corte Constitucional Colombiana ${ }^{2}$ ha sido protagónica en los últimos años en el escenario constitucional y político de la región. Su jurisprudencia ha sido considerada progresista y pertinente para acompañar reivindicaciones sociales por la igualdad y la justicia social. En este contexto, han sido visibilizadas dos sentencias hito: en primer lugar, la sentencia T-025 de 2004 que declaró el estado de cosas inconstitucional ${ }^{3}$ respecto de una situación extrema y hasta irrazonable en un régimen político al que se endilga la estabilidad democrática más preciada de América Latina: los más de $\mathbf{4 . 0 0 0 . 0 0 0 ~ d e ~ d e s p l a z a d o s ~ q u e ~ v i v e n ~ e n ~ l a ~ p o b r e z a ~ y ~}$

\footnotetext{
${ }^{2}$ La Corte Constitucional es un Tribunal creado por la Constitución Colombiana de 1991, al cual se le encargó la función de garantizar la primacía de la Constitución en el ordenamiento jurídico nacional. Esta labor se cumple a partir del desempeño de funciones como el estudio de acciones de inconstitucionalidad que cualquier ciudadano puede interponer contra una norma, así como con la revisión y pronunciamiento sobre los fallos de tutela o amparo que dictan los jueces en todo el país, y finalmente, estudiando de oficio otras normas como los decretos relacionados con estados de excepción, presupuesto, entre otras.

${ }^{3}$ El estado de cosas inconstitucional hace referencia a la sistemática y masiva violación de derechos humanos a una comunidad o grupo de población.
} 


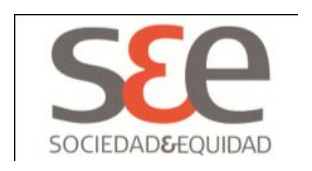

miseria por la destrucción violenta de su proyecto de vida. En segunda lugar, la sentencia T-760 de 2008, que igualmente declaró el estado de cosas inconstitucional respecto a algunos elementos del sistema de salud. En ambos casos se trató de situaciones extremas y que en sí mismas resultaban evidentemente inaceptables, tanto desde el punto de vista constitucional, como desde el punto de vista general de la población ${ }^{4}$.

No obstante, estas sentencias no significan una ruptura estructural con el actual modelo de distribución de riqueza. El que promueve la concentración de los medios de producción y de los negocios productivos en las grandes empresas que durante años se han favorecido con la exclusividad en la explotación de una actividad económica. Por el contrario, otros pronunciamientos de la Corte Constitucional, no tan publicitadas, se ajustan más a la idea de quebrar la lógica de acumulación de capital monopólica que ofrece la generación de empleo como camino idóneo para superar la pobreza, sino que amplían las posibilidades para incluir a sectores marginados en el proceso de explotación económica en condiciones de igualdad, y conforme a sus habilidades y saberes.

En la línea jurisprudencial desarrollada por la Corte Constitucional sobre las medidas que deben desplegar las autoridades públicas para asegurar los derechos de la población dedicada a la recuperación de residuos sólidos o recicladores, se desarrollan varios elementos fundamentales para una nueva compresión de qué es la pobreza y cuáles serían las estrategias más pertinentes para erradicarla. Los planteamientos desarrollados en estas sentencias suponen comprender la pobreza no solo como la ausencia de recursos económicos y financieros, sino como la carencia de reconocimiento social del saber y aporte que sectores, públicamente despreciados, hacen y pueden hacer al desarrollo social. $Y$ con relación a las medidas más adecuadas para superar tal situación de pobreza, el lente constitucional nos llama la atención para que las políticas sociales que se propongan en este sentido giren hacia la construcción de modelos institucionales de inclusión productiva, más allá de la generación de empleo ${ }^{5}$, que a su vez

\footnotetext{
${ }^{4}$ El posicionamiento público de estas dos sentencias ha trascendido significativamente la dinámica institucional, incluso La Corte se transformó orgánicamente y dispuso salas de seguimiento al cumplimiento de las órdenes y creó cargos de Magistrado Auxiliar para asegurar tal seguimiento.

${ }^{5}$ Estudios sobre la pobreza en América Latina suelen identificar la falta de empleo con la pobreza, en consecuencia, proponen como salida a esta última la necesaria búsqueda del crecimiento económico para que puedan generarse más puestos de trabajo. Por ejemplo, el último informe del Observatorio Latinoamericano de pobreza (2010), señala que la superación de la pobreza requiere de tasas de crecimiento sostenido entre el $6 \%$ y $7 \%$ anual, con el objetivo de romper el círculo vicioso de la pobreza y a través de mejoras en el sistema educativo, aumentar las posibilidades de vinculación a un empleo. No obstante, la generación de empleo no altera la estructura monopólica de explotación productiva, que propicia la concentración de la riqueza y que causa la pobreza y la profunda desigualdad existente en la región.
} 


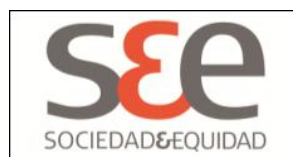

supone, reconocer las capacidades y conocimientos que sectores de la sociedad pueden aportar para el mejoramiento de la calidad de vida de toda la población. Cuando se piensa en generar empleo, se observa a un sujeto más que puede hacer parte de cualquier eslabón de la cadena productiva, se refiere a un número; mientras que cuando se piensa en el desarrollo colectivo para la prestación de un servicio público, se ve al ciudadano y a la comunidad de ciudadanos con capacidades y potencialidades particulares para hacer parte de la solución de un problema público.

\section{Los recicladores y la Jurisprudencia Constitucional Colombiana}

En el estudio de las sentencias de los jueces resulta muy útil la metodología de líneas jurisprudenciales desarrollada por Diego López Medina. Esta técnica busca como resultado construir un relato sobre las distintas decisiones judiciales que a lo largo del tiempo se han adoptado para resolver un problema jurídico, que a su vez, es una pregunta de investigación. En esta oportunidad, la pregunta que orientó este trabajo fue ¿cuál es la medida de política pública idónea constitucionalmente para asegurar el derecho a la vida digna de la población de recicladores, en el marco de las decisiones gubernamentales relacionadas con la prestación del servicio público de aseo? Para responder esta pregunta se identificaron las sentencias de la Corte Constitucional que han tratado situaciones fácticas semejantes. Las providencias encontradas fueron las sentencias de tutela T-724 de 2003, T-291 de 2009, T-387 de 2012 y los Autos de cumplimiento de la primera sentencia enunciada, Auto 268 de 2010 y Auto 275 de 2011.

Con base a la revisión de estas sentencias y siguiendo la metodología de Diego López Medina, identificamos subreglas jurisprudenciales, es decir, planteamientos generales que responden al problema jurídico o pregunta de investigación propuesto. Por tanto, esta sección del documento se estructura con base a estas subreglas.

A. La población de recicladores son sujetos de especial protección constitucional por tratarse de un grupo tradicionalmente discriminado y excluido, y por la labor ambiental que desempeñan, de la cual toda la sociedad resulta beneficiaria.

Tradicionalmente se ha identificado una lista de grupos marginados y discriminados, que por encontrarse en tal condición, son sujetos de especial protección y deben beneficiarse de la mayor parte del esfuerzo gubernamental. Por ejemplo, a través de medidas afirmativas que les permita gozar de los mismos derechos de que disfrutan quienes no padecen tales discriminaciones y tal 


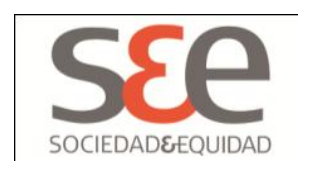

marginación social. Suele identificarse de manera explícita en dicha lista a las mujeres, las personas de la tercera edad y los niños, entre otros. No obstante, la Corte Constitucional ha identificado otros grupos con base a los siguientes criterios:

De conformidad con la jurisprudencia de esta Corporación, y tan solo a manera de ejemplo, un grupo marginado puede estar compuesto por (i) personas que por su condición económica, física o mental, se hallan en circunstancias de debilidad manifiesta; ${ }^{6}$ (ii) personas que en razón de la situación desventajosa en la que se encuentran, suelen ver limitado el ejercicio y el goce efectivo de sus derechos fundamentales; ${ }^{7}$ (iii) diminuidos (sic) físicos, sensoriales y psíquicos que son objeto de aislamiento, estigmatización, maltrato, incomprensión o discriminación lo cual conduce a su marginamiento; ${ }^{8}$ (iv) población en situación de extrema pobreza, o en condiciones de manifiesta injusticia material y vulneración de la dignidad humana; ${ }^{9}$ o (v) un grupo de la población que no está en capacidad de participar del debate público y que, por lo tanto, no tiene voz propia en la adopción de las decisiones políticas que lo afectan ${ }^{10}$

La precaria calidad de vida de los recicladores fue visibilizada en la Corte y allí se mencionó que "además de acometer su trabajo en condiciones que los exponen al agua, al sol, y a residuos peligrosos, según estudios realizados, son más propensos a obtener enfermedades trasmitidas por los parásitos, moscas y mosquitos. De igual modo, sufren con frecuencia irritaciones en la piel y erupciones, al igual que tuberculosis, bronquitis, asma, neumonía y disentería”

\footnotetext{
${ }^{6}$ Corte Constitucional, Sentencia T-401 de 1992, donde se tutelaron los derechos de convictos inimputables sujetos a una injusta y prolongada privación de su libertad, a pesar de haber cesado el motivo de la correspondiente medida de seguridad.

${ }^{7}$ Sentencia T-595 de 2002.

${ }^{8}$ Sentencia T-255 de 2001, donde la Corte tutela el derecho a la educación de un menor de edad a quien no se le había renovado el cupo en el colegio, porque el centro educativo afirmaba no estar preparado para impartir educación especial a un niño hiperactivo.

${ }^{9}$ Sentencia T-177 de 1999.

${ }^{10}$ Sentencia SU-225 de 1998.
} 


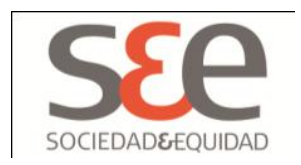

(Wiego, 2010). En este sentido, en un estudio realizado en el dos mil siete (2007) en la Ciudad de Medellín, se evidenció que:

el 36\% de los recicladores encuestados declaró haberse sentido enfermo en los 15 días previos a la entrevista. La frecuencia relativa fue mayor en las mujeres (56\%) que en los hombres (26\%). Entre las personas encuestadas, el $37 \%$ manifestó padecer infecciones respiratorias agudas, y en menor proporción enfermedades diarreicas, enfermedades de los dientes, y otras inespecíficas. En la valoración médica a los 49 asistentes, la patología más frecuentemente diagnosticada fue la correspondiente a enfermedades de los órganos de los sentidos (25\%), seguidas de enfermedades del sistema circulatorio (18\%), algo más frecuentes en hombres que en mujeres (Gómez-Correa et al., 2010).

Además, destacó la Corte que esta población se encuentra en situación de explotación, dado que de los millones de dólares que produce el negocio del reciclaje al año, ellos reciben solo un 5\%, según informe del Asesor del Banco Mundial en materia de residuos sólidos, debido justamente a la explotación monopólica de esta actividad económica. La condición de exclusión y marginación social también fue verificada por la Corte y afirmó que "la sociedad rechaza la basura y extiende dicho rechazo a quienes trabajan con ella"11, promoviéndose incluso, la mal llamada limpieza social para eliminar su existencia.

Con base a todos los elementos que rodean la situación de la población dedicada al reciclaje, concluyó la Corte que se trata de sujetos de especial protección, reconocimiento que también deriva del beneficio colectivo que se genera por su actividad ecológica y de salvaguarda de medio ambiente, del que disfruta la sociedad en general. Por ejemplo, el reciclaje permite que sean menos los desechos que lleguen a los rellenos sanitarios, y por tanto, reduce el uso de agentes contaminantes presentes en la destrucción de materiales en los rellenos, a la vez que se prolonga la vida útil de estos últimos. La ciudadanía debe valorar el significativo aporte que esta población hace a toda la sociedad, reconociendo sus conocimientos y capacidades en la labor del reciclaje y en el cuidado del medio ambiente.

\footnotetext{
${ }^{11}$ Sentencia T-291 de 2009, MP. Clara Helena Reales Gutiérrez.
} 


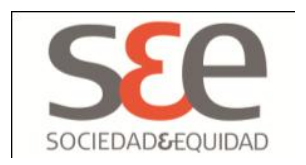

B. Las medidas afirmativas en los procesos de contratación pública que se promuevan a favor de los recicladores deben permitirles continuar desarrollando su actividad, fortalecer su capacidad organizativa y consolidarse como empresarios del reciclaje, por tanto, tales acciones no deben limitarse a vincularlos laboralmente a las grandes empresas de aseo y reciclaje.

En la sentencia T-724 de 2003, la Corte Constitucional estudió el caso en el que la Unidad Ejecutiva de Servicios Públicos de Bogotá (UESP) convocó en la licitación pública No. 01 de 2002, un proceso de selección para adjudicar, mediante contrato de concesión, la prestación del servicio público de aseo en la capital. En esta licitación se estableció que sólo podrían participar los operadores que habían prestado este servicio en la ciudad desde mil novecientos noventa y cuatro (1994). El Alto Tribunal seleccionó este caso para revisión y afirmó que la UESP vulneró los derechos fundamentales de la Asociación de Recicladores de Bogotá (ARB), dado que la Licitación Pública No. 01 de 2002 no incluyó medidas afirmativas idóneas a favor de la población dedicada al reciclaje, teniendo en cuenta que se trata de un grupo discriminado y marginado. Al contrario, consideró que la actuación de la UESP profundizaba la situación de marginación de esta población por dos razones: 1) La única medida afirmativa contenida en el pliego de condiciones establecía que el $15 \%$ de los operarios requeridos para el corte de césped deberían ser personas en situación de desplazamiento y recicladores, no obstante, esta medida resultaba ineficaz dado que se trataba de una actividad diferente a la de reciclaje, y el 15\% a contratar incluyó a otras personas en condición de debilidad manifiesta, como lo es la población víctima del desplazamiento. 2) La política de la UESP de dejar en manos de los concesionarios la actividad de recuperación de materiales sólidos reutilizables y excluir a los recicladores de la misma, acentuaba las condiciones de marginación y exclusión social de esta población.

Dado que, a la fecha de la sentencia T-724 de 2003, el contrato de concesión había sido adjudicado, la orden de la Corte consistió en prevenir a la UESP o a la entidad del Distrito que haga sus veces, para que en futuras licitaciones y sin excusa alguna, incluyera acciones afirmativas a favor de los recicladores cuando se trate de la contratación de servicios públicos de aseo, pues la actividad del reciclaje está relacionada con este servicio. Todo esto, con el objeto de crear condiciones reales para la igualdad sustantiva y dar cumplimiento a los deberes sociales del Estado. La Corte valoró profundamente la importancia de incluir a los recicladores en la prestación del servicio público de aseo, y en 


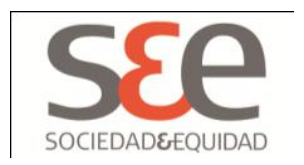

general, la relevancia que en un Estado Social de Derecho tiene la superación de la marginación y la exclusión, que causa y profundiza la pobreza.

Adicionalmente, este Tribunal enfatizó la importancia de que en general se incluyeran medidas afirmativas en todos los procesos licitatorios de contratación Pública, dado que la Ley 80 de 1993 no prevé nada al respecto y la inexistencia de tales acciones desconoce el mandato del artículo 13 de la Constitución Política. Por tanto, exhortó al Consejo de Bogotá para que incluyera acciones afirmativas en todos los procesos de contratación administrativa, a favor de los grupos marginados y excluidos que requieren protección especial del Estado. Es decir, no solo cuando se tratara de licitaciones para el servicio público de aseo, sino en general para todos los procesos.

En esta primera sentencia sobre el tema, la Corte Constitucional determina tres elementos muy importantes para delinear las medidas de política pública de superación de la marginación de los grupos tradicionalmente excluidos y el avance hacia el logro de la igualdad sustantiva: 1) Las medidas afirmativas profundizan la situación de marginación social de un grupo de ciudadanos, cuando incluyen dentro de un mismo proceso, a otras personas que se encuentran también en condiciones de marginalidad, exclusión y/o debilidad manifiesta. 2) La medida afirmativa debe favorecer que las personas continúen desarrollando y fortaleciendo su actividad de subsistencia, y por tanto, no pueden las autoridades públicas excluirlas del desarrollo de esta actividad para entregársela exclusivamente a grandes empresas concesionarias, sino que debe promoverse su capacidad organizativa para que sean empresarios del reciclaje, más que empleados de las grandes empresas.

C. Las medidas afirmativas deben ser idóneas para lograr el mayor impacto posible a favor de la inclusión del grupo marginado, no basta con incorporar la participación de unos pocos, sino que con base a la estructura organizativa de dicho grupo, deben proponerse acciones que incluyan al mayor número de personas.

En el año 2010, la Alcaldía de Bogotá inició una nueva licitación para contratar en la modalidad de concesión a la administración, operación y mantenimiento integral del relleno sanitario Doña Juana de la ciudad de Bogotá. En esta ocasión, la Corte determinó, en el Auto 268 de 2010, que se estaba incumpliendo lo dispuesto por la sentencia T-291 de 2009, dado que las medidas afirmativas contempladas en esta nueva licitación no eran eficaces. Dichas medidas consistían en establecer como tercer criterio de desempate la participación accionaria de grupos de base de recicladores en la empresa 


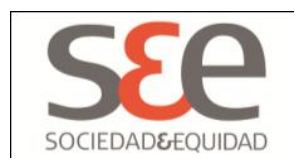

proponente $^{12}$, y como criterio habilitante que dicha empresa tuviese como integrantes una organización de base. No obstante, la participación de esta población no aparecía como criterio en la puntuación para la calificación de las propuestas, situación que a juicio de la Corte resultaba insuficiente.

En este orden de ideas y teniendo en cuenta lo señalado en la sentencia T291 de 2009, la participación de los recicladores, que no sólo debe darse como trabajadores sino como empresarios de las basuras, sólo puede garantizarse si esta circunstancia se constituye como un criterio de calificación adicional a la nacionalidad y a la oferta económica, pues es un incentivo para que los proponentes postulen formas cualitativas de vinculación representativa de esta población. Además, de lo que se trata es de reivindicar el trabajo realizado por los recicladores, dadas sus evidentes e indudables funciones ambientales, es necesario que en la licitación se fijen criterios de calificación para el proyecto de aprovechamiento, de tal forma que los proponentes busquen alcanzar hasta el máximo posible de residuos a aprovechar, lo que se relaciona también con la mano de obra recicladora disponible que se requerirá (Corte Constitucional, 2010:45).

Es decir, en los procesos licitatorios debe ser tan importante la participación de los recicladores que les permita consolidar su organización y su condición como empresarios del reciclaje, como la calificación del proyecto de aprovechamiento de residuos sólidos, que además de garantizar la continuidad del trabajo de esta población, cuida el ambiente y aumenta la vida útil de los rellenos sanitarios.

El criterio central que tuvo la Corte para desestimar la idoneidad de estas medidas es que, además de no ser criterios de calificación de las propuestas, sino que solo eran de desempate y de habilitación para la presentación, en sí mismas las medidas no eran representativas de toda la población de reciclaje y por tanto no eran realmente inclusivas. Esto debido a que la medida exigía que la empresa proponente estuviese asociada con una organización de base, que incluso puede agrupar a solo una persona, mientras que las organizaciones de segundo nivel, típica de la estructura organizativa que la misma alcaldía de Bogotá ayudó a conformar $^{13}$, agrupan a varias organizaciones de base y reúnen en un solo caso hasta más de 2000 recicladores. La medida debe fortalecer e incluir al mayor

\footnotetext{
${ }^{12} \mathrm{La}$ empresa proponente es la que presenta oferta dentro del proceso de licitación para la adjudicación de contrato.

${ }^{13}$ La UESP de la Alcaldía de Bogotá firmo convenios con el objeto de promover procesos asociativos y fortalecer la gestión económica y social de las organizaciones de recicladores. A partir de este trabajo, se conformaron tres organizaciones de segundo nivel, cada una de las cuales reúne a varias organizaciones de base, y con 2011, 626 y 750 miembros respectivamente, mientras que las organizaciones de base tienen sólo hasta 85 miembros.
} 


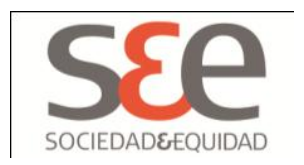

número de personas posibles, y por supuesto, este impacto solo puede lograrse si se exige a los proponentes asociarse con organizaciones de segundo nivel.

En consecuencia, la Corte ordenó que se incluyera, como criterio habilitante, que los proponentes estuviesen asociados con organizaciones de segundo nivel, y como criterios de calificación, la participación accionaria de estas organizaciones dentro de la empresa proponente y la magnitud de residuos sólidos a aprovechar, haciendo especial énfasis en la mano de obra ${ }^{14}$.

En el año 2011, la Alcaldía de Bogotá abrió un nuevo proceso licitatorio para concesionar el servicio público de aseo en los componentes de recolección, transporte, limpieza, corte de césped y poda de árboles. Esto provocó un nuevo pronunciamiento de la Corte, ya que si bien incorporó las medidas que fueron ordenadas en el Auto 268 de 2010, el Alto Tribunal consideró que para el caso concreto de licitación de toda la cadena de servicios del servicio público de aseo, tales medidas no cumplían con la característica de ser afirmativas. A esta conclusión llegó la Corte tras afirmar que estas medidas deben ser independientes, es decir, que su realización en sí misma debe causar un favorecimiento del grupo marginado, pero en este caso consideró que: 1) La participación accionaria de las asociaciones de reciclaje no causaba dividendos a favor de los recicladores, dado que son sin ánimo de lucro, y tales recursos no pueden distribuirse entre los asociados, por tanto, pueden ser usados en actividades que no guardan relación directa con la actividad del recicle. Así lo concluye de la lectura de algunos estatutos en los que el cuidado ambiental o donaciones a fundaciones era el destino final de tales dineros. 2) La asignación de rutas de reciclaje no es una acción afirmativa, ya que no es independiente, pues está sujeta a acciones que el oferente quiera o no ejecutar. 3) La igualdad entre las asociaciones de reciclaje resulta afectada pues la forma y tiempos de asignación de dividendos varía según lo disponga el oferente con el que se asocien.

En este Auto, la Corte afirmó que dado que los recicladores son un grupo discriminado y minoritario, "los intereses de los proponentes involucrados en el trámite de la licitación pública 001 de 2011 -también particulares- deben desplazarse en este caso a favor de los derechos de las minorías que por esta vía se pretende proteger"15. Máxime, si el proceso de licitación se encuentra en etapa precontractual y aún no se ha consolidado la contratación pública, "privilegiar los derechos del trabajo y la dignidad humana de las minorías dedicadas al reciclaje

\footnotetext{
${ }^{14}$ Estas órdenes resultaron completamente viables y no lesivas de los derechos contractuales de los proponentes, dado que no se había adjudicado ningún contrato. Por tanto se concedió un plazo a dichos proponentes para que cambiaran sus ofertas de acuerdo a estos criterios.

${ }^{15}$ Auto 275 de 2011.
} 


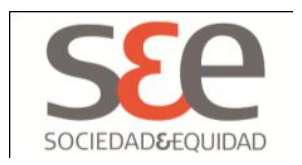

por encima de las expectativas comerciales de los particulares que participan en condición de oferentes y que bien pueden hacerse presentes en futuros procesos de selección, no encuentra reparo alguno para esta sala de revisión". ${ }^{16}$

Finalmente, en esta ocasión la Corte dejó sin efecto la licitación pública No. 001 de 2011 y todos los actos administrados que se hubiesen proferido en desarrollo de la misma, en orden a que el Distrito defina y rediseñe un esquema que dignifique la actividad del reciclaje y que tienda a su normalización, a través de la fijación de metas a cumplir en el corto plazo que sean concretas, cualificadas, medibles y verificables. (...) Dicho Plan deberá contener acciones afirmativas en favor de la población que se dedica de manera permanente a la actividad de reciclaje -lo que supone un enfoque diferencial-, de manera que se logre su regularización respecto de la prestación de los servicios complementarios de aseo en los componentes de reciclaje, transporte, transformación y aprovechamiento de residuos.

En el Auto 275 de 2011, la Corte se pregunta por las posibles consecuencias negativas al interés general, producto de la suspensión del proceso de licitación pública del servicio de aseo en Bogotá, ordenada por el Alto Tribunal. Ello a raíz de que no incorporaba medidas afirmativas idóneas para la población de recicladores. Esta Corporación destacó que la administración pública tiene a su disposición herramientas que de hecho fueron usadas para asegurar la continuidad en la prestación del servicio, como la suscripción de contratos por el mecanismo de urgencia, quedando satisfecho el interés general.

D. Cualquier medida de política pública que afecte a un grupo de personas debe implementar simultáneamente las acciones que permitan el goce de los derechos de la comunidad afectada, máxime si se trata de un grupo de especial protección y la administración ha hecho promesas al respecto.

La sentencia T-291 de 2009 estudió el caso del cierre del basurero de Navarro de la ciudad de Cali, a partir de varias sentencias de tutelas acumuladas. Los ciudadanos que interpusieron la acción de tutela fueron 30 recicladores que derivaban su sustento de dicho basurero y si bien dos semanas antes del cierre suscribieron un acta en la que las autoridades locales se comprometían a ofrecerles oportunidades de empleo, capacitación, salud y educación, esto no fue cumplido.

\footnotetext{
${ }^{16}$ Auto 275 de 2011.
} 


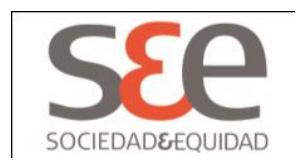

En esta sentencia la Corte reiteró que la población de recicladores es un grupo social tradicionalmente discriminado y excluido, porque viven en condiciones de extrema pobreza y están sujetos a estereotipos que los marginan socialmente, por trabajar con lo que la sociedad desecha. Incluso, la exclusión y marginación de este grupo social ha causado la ejecución de la mal llamada limpieza social para eliminarlos de la sociedad.

La sociedad rechaza la basura y extiende dicho rechazo a quienes trabajan con ella. Son personas que recogen basuras de manera informal ante la ausencia de otros medios de subsistencia, no debe sorprender que si las personas "solo encuentran oportunidades en los desperdicios de los demás, es porque no tienen otras opciones de trabajo y de sustento a su disposición (Corte Constitucional, 2009: 35).

La Corte analizó la medida del cierre del botadero Navarra, haciendo referencia a otras medidas implementadas en Cali, en el marco de la política pública de prestación del servicio público de aseo, y que igualmente afectan desproporcionalmente a los recicladores informales: la prohibición de separar y clasificar basura en vías públicas ${ }^{17}$, destapar o extraer parcialmente y sin autorización el contenido de las bolsas de basura colocadas en la calle para su recolección ${ }^{18}$, el transporte de desechos en vehículos no aptos o adecuados, como los de tracción animal ${ }^{19}$, la prohibición de la presencia de recicladores en el frente de trabajo de los rellenos sanitarios ${ }^{20}$.

El cierre del botadero Navarro obedeció a la finalidad constitucional, imperiosa de garantizar la salubridad pública, debido a la contaminación del medio ambiente y los efectos nocivos en la población que causan los basureros a cielo abierto. Por tanto, la medida resultó adecuada y necesaria, en tanto "no había nada que hacer para permitir su operación en condiciones ambientalmente óptimas" ${ }^{21}$. Y dado que la medida afectó directamente la satisfacción de las necesidades básicas de los recicladores que derivaban su sustento del material

\footnotetext{
${ }^{17}$ Art. 23 de la Ley 9 de 1979.

${ }^{18}$ Art. 5, numeral 6 de la Ley 1259 de 2008.

${ }^{19}$ Art. 5, numeral 15 de la ley 1259 de 2008.

${ }^{20}$ Art. 86 del Decreto 1713 de 2002, modificado por el art. 9 del decreto 1505 de 2003.

${ }^{21}$ Sentencia T-291 de 2009, M.P. Clara Helena Reales Gutiérrez.
} 


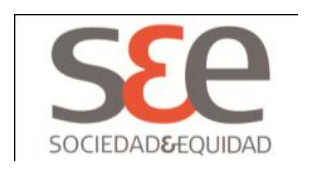

reciclable del botadero Navarro, la administración municipal debió diseñar y ejecutar simultáneamente medidas que aseguraran no sólo la satisfacción del mínimo vital de estas personas para contrarrestar de manera inmediata el daño causado, sino que además debió implementar las estrategias adecuadas y necesarias para mejorar las condiciones de vida del grupo social marginado.

En este contexto, las autoridades del municipio de Cali, tras el cierre del botadero Navarro: a) Actuaron negligentemente pues no diseñaron una respuesta adecuada para atender las consecuencias adversas del cierre del botadero, pese a que habían transcurrido 10 años desde la decisión del cierre. b) Omitieron su deber de especial protección a un grupo social marginado y afectado por el cierre del botadero. c) Desconocieron el principio de confianza legítima al incumplir los compromisos adquiridos con los recicladores dos semanas antes del cierre del botadero, en el marco de un proceso de negociación promovido por la misma administración municipal, "en momentos de tensión que hubiesen podido retrasar el cierre del basurero"22.

Para la Corte, una alternativa adecuada, más que convertir a los recicladores en empleados de las grandes empresas, es permitir y promover que actúen como empresarios, promoviendo su capacidad organizativa y fortaleciendo sus capacidades y oportunidades para seguir ejerciendo la actividad que han venido desarrollando. Por tanto, la generación de empleo por tres (3) ó (5) meses es una medida coyuntural que no genera alternativas económicas duraderas para esta población.

La Corte ordenó que, dentro de los dos meses siguientes, se adoptaran las medidas necesarias para asegurar el goce efectivo de los derechos constitucionales a la salud, a la educación, a la vivienda digna y a la alimentación, verificando en cada caso la afiliación al Sistema de Seguridad Social en Salud, el acceso a la educación para menores de edad, y su inclusión en los programas sociales de la Alcaldía en asuntos de alimentación y vivienda.

Igualmente, ordenó a la Alcaldía de Cali, en coordinación con la Empresa de Servicio Público de Cali "EMSIRVA ESP", o la que la reemplace, la Corporación Autónoma Regional del Valle y el Departamento Administrativo del Medio Ambiente, vincular a los accionantes a las alternativas laborales y de subsistencia prometidas en las actas y en el Plan Integral de Gestión de Residuos Sólidos (PIGRS): “(1) soluciones temporales de trabajo para garantizar la subsistencia, (2) soluciones de negocio para garantizar la subsistencia y (3) soluciones periféricas a la subsistencia".

\footnotetext{
${ }^{22}$ Sentencia T-291 de 2009, M.P. Clara Helena Reales Gutiérrez.
} 


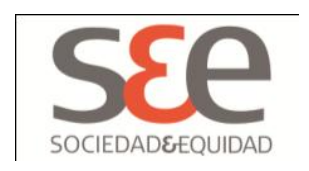

Finalmente, la Corte dictó órdenes complejas para garantizar el proceso de inclusión de los recicladores de Navarro y los llamados recicladores de la ciudad de Cali:

1. Suspensión por tres (3) meses de la Convocatoria Pública No. 002 de 2009, cuyo objeto es la celebración del "Contrato para la operación y explotación de los servicios de recolección de los residuos sólidos, el barrido y la limpieza de vías y áreas públicas, la gestión comercial y otras actividades en la zona $\mathrm{N}^{\circ} 1$ de la ciudad de Cali”,

2. Reformular dentro de los tres (3) meses de suspensión los términos de la Convocatoria Pública No. 002 de 2009 para:

2.1. Fijar condiciones dentro de los términos de referencia que permitan a los recicladores participar en la actividad de recolección y aprovechamiento de residuos, estimulando no sólo su vinculación laboral, sino que se desempeñen como empresarios de la basura.

2.2. En ningún caso los recicladores del basurero Navarro y los recicladores de la calle pueden ser excluidos del proceso de reciclaje.

2.3. Las convocatorias futuras que se realicen para la recolección de basuras y el aprovechamiento de residuos sólidos deben privilegiar y tratar de preservar la calidad de empresarios autónomos de los recicladores.

2.4. Adoptar como criterio de puntuación en la licitación para la recolección de basuras y el aprovechamiento de residuos sólidos, la participación de los recicladores, no solo cuando sean contratados laboralmente, sino especialmente cuando favorezcan formas asociativas que aseguren su continuidad como empresarios de la basura.

\footnotetext{
${ }^{23}$ T-291 de 2009, M.P. Clara Helena Reales Gutiérrez.
} 


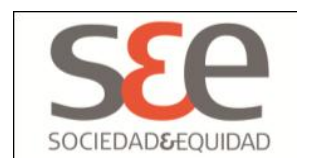

A comienzos del año 2012, la Corte Constitucional expidió la sentencia T-387 de 2012, en la que adopta una decisión deslineada en relación con la jurisprudencia expuesta hasta aquí, en tanto consideró que el hecho de que los recicladores tuviesen a cargo una ruta de recolección, era una medida afirmativa idónea, sin considerar la proporción entre el número de recicladores que quedarían por fuera de la prestación del servicio de aseo en la ciudad, ya que solo tendrían una ruta a su disposición para la recolección, pero quedarían por fuera de la empresa encargada de todo el servicio de aseo.

La Alcaldía de Popayán inició en el 2007 el proceso licitatorio No. 67 con el objeto de vincular socios estratégicos para conformar la Empresa de Servicio Público de Aseo de Popayán. El primer pliego de condiciones de esta licitación fue revocado por la administración municipal, dado que no contenía acciones afirmativas a favor de los recicladores. En el nuevo texto se incluyeron las siguientes acciones afirmativas, haciendo alusión a la sentencia T-291 de 2009: a) Contratación prioritaria de personas dedicadas al reciclaje y aprovechamiento de residuos, y que estén organizadas en cooperativas u otras formas asociativas. b) Asignación de la ruta de recolección selectiva a los recicladores organizados del municipio de Popayán, para lo cual la Alcaldía se comprometió a disponer un vehículo tipo furgón y ordenó a la nueva empresa de aseo la asignación de un conductor y un tripulante para su manejo. A su vez dispuso que esta última no estuviera a cargo de la actividad de recolección y transporte de los residuos aprovechables obtenidos mediante la ruta de recolección selectiva. c) Destinación de recursos, que podrían provenir del recaudo mensual a la nueva empresa de aseo, para programas dirigidos a los recicladores.

Para la Representante Legal de la Asociación de Recolectores de Materiales Reciclables de Popayán (AREMARPO), estas acciones afirmativas resultaban paternalistas y reproductoras de la exclusión, ya que no exigía que uno de los cinco (5) socios fuese una asociación de recicladores y tampoco puntuaba en la calificación de las propuestas la participación de recicladores.

La Corte estudió en la sentencia T-387 de 2012 la idoneidad de estas medidas afirmativas y concluyó que debido a las condiciones fácticas particulares de este caso, en el que no se había despojado a los recicladores de su actividad productiva, las medidas implementadas por la Alcaldía de Popayán resultaban idóneas y ajustadas a la jurisprudencia precedente, ya que la efectividad e incidencia real de una medida afirmativa debe valorarse en las condiciones particulares de cada caso.

Para la Corte, en este caso no se estaba despojando a los recicladores de su fuente de trabajo, sino que se estaba dejando a su cargo exclusivamente, ya que en el pliego de condiciones se estableció que la nueva empresa prestadora del servicio de aseo no estaría a cargo de la actividad de recolección y transporte de 


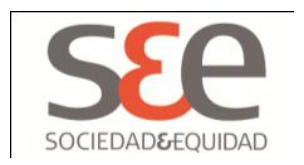

los residuos aprovechables que se obtuviesen mediante ruta de recolección selectiva, toda vez que dicha actividad estaría a cargo de los recicladores organizados. Por tanto, si se implementara como medida afirmativa, la participación accionaria de los recicladores, sería inocuo, ya que actualmente son propietarios de los residuos sólidos que recolectan, mientras que si tuviesen la calidad de accionistas cederían al contratista un porcentaje de la titularidad sobre esos residuos.

Agregó la Corte, que en la Escritura Pública 399 de 2001, mediante la cual se constituyó la Sociedad Serviaseo Popayán S.A. E.S.P., se estipuló en su parte final: “(...) la actividad del reciclaje es y será de los recicladores, (...); así mismo, expresan su voluntad de celebrar un convenio con las organizaciones privadas que desarrollan la actividad del reciclaje, con el fin de garantizar sus derechos durante el tiempo de vigencia de la sociedad"24.

Finalmente, la Corte destaca la invitación pública de la Empresa Serviaseo de Popayán S.A. E.S.P. a los recicladores para su vinculación laboral, aunque esta no constituya una medida afirmativa, sino asistencial. La firma del Convenio Abierto 10 del 1 de abril de 2011, en el que se concertaron los criterios operativos de la ruta de recolección selectiva y la campaña "Ray-mundo-Reciclando ayuda al mundo", para crear la cultura del reciclaje y ayudar a los recicladores.

El Alto Tribunal concluyó que la Alcaldía de Popayán no despojó a los recicladores de su actividad laboral y adoptó medidas para apoyar y mejorar sus condiciones de trabajo y proyectar su trabajo como empresarios. No obstante, consideró que era necesario garantizar la independencia y eficacia de la implementación de las acciones afirmativas y ordenó la expedición de un acto administrativo en el que se incluyeran formalmente las acciones a implementar, la forma de llevarlas a cabo y sus objetivos, para asegurar su ejecución pese al cambio de administración y mejorar constantemente la situación de la población recicladora. Igualmente, ordenó el acompañamiento de la Defensoría del Pueblo y la Procuraduría General de la Nación para que observe el cumplimiento de las acciones dirigidas a la población recicladora.

\section{La interpretación Institucional de los Derechos de Thomas Pogge}

El profesor Thomas Pogge expone en su libro, "La pobreza en el mundo y los derechos humanos", una interesante interpretación de los mismos, a la que llama Institucional. Pogge, más que desarrollar una doctrina sobre el contenido de los bienes objeto de los derechos, se preocupa por la idoneidad del orden social que

\footnotetext{
${ }^{24}$ Sentencia T-387 de 2012, M.P. Jorge Ignacio Pretelt Chaljub.
} 


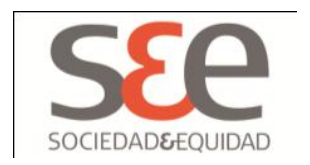

hay que consolidar para asegurar a todas las personas, especialmente a los más pobres, el acceso seguro a tales bienes. "Los derechos son demandas morales que atañen a la organización de la propia sociedad” (Pogge, 2005: 90).

El autor fundamenta esta afirmación diciendo que debe existir un orden social que garantice la concreción de los derechos humanos en la medida más razonable posible. La responsabilidad de lograr este orden social es del Estado y de los ciudadanos, especialmente los más privilegiados, quienes deben aportar para la estructuración de un orden institucional que asegure el acceso a los objetos de los derechos humanos. La ausencia de este orden institucional es un problema real de derechos humanos.

Pogge hace este análisis respecto de las instituciones globales, ya que su trabajo se centra en la pobreza en el mundo, por ello afirma que la pobreza, que se traduce en hambre y otras carencias, son consecuencia directa de los esquemas institucionales impuestos por los países ricos, y que ya están interrelacionados con las Instituciones locales de los países que albergan a los pobres del mundo:

Los ciudadanos y los gobiernos de los países ricos -ya sea intencionalmente o no- están imponiendo un orden institucional global que de manera previsible y evitable reproduce una pobreza extrema y ampliamente extendida. Los menos favorecidos no son simplemente pobres que a menudo mueren por falta de alimentos, sino personas a las que se empobrece y se mata de hambre bajo los esquemas institucionales que compartimos con ellas, y que inexorablemente configuran sus vidas (Pogge, 2005: 255)

Concuerdo con Pogge en que la satisfacción de los derechos no es posible si las estructuras sociales no generan las instituciones y dispositivos suficientes para asegurar el goce pleno de los derechos. No bastan las estructuras normativas que enlisten garantías jurídicas; es necesario que la sociedad se configure a favor de los derechos humanos. No obstante, y antes de discutir este planteamiento con las sentencias a las que se ha hecho alusión, vale la pena hacer una aclaración sobre los planteamientos de este autor, respecto de los cuales disiento.

El aporte que este autor hace a la teoría de los derechos humanos radica en que es imprescindible cuando se piensa en la satisfacción de los derechos humanos, que no son las normas jurídicas, sino los bienes objeto de los mismos, como los alimentos, medicamentos, las escuelas, las universidades, etc., siguiendo el planteamiento de Joaquín Flores (2008) sobre qué son realmente los Derechos 


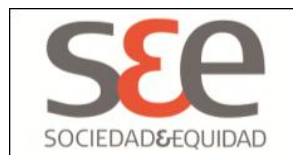

Humanos ${ }^{25}$, dejar de lado la reconfiguración de un orden institucional que asegure de manera efectiva el acceso seguro a esos bienes.

Cabe entonces la pregunta para Pogge, ¿qué características debe tener ese nuevo orden institucional? Aquí es cuando la jurisprudencia constitucional colombiana enriquece significativamente este planteamiento. El elemento común encontrado en la línea jurisprudencial que se describió es que no sólo ordena a las autoridades hacer algo para garantizar efectivamente los derechos de vida digna de un grupo discriminado, sino que dicha orden motiva la reconfiguración institucional para desmonopolizar la prestación del servicio público de aseo, e incluir en esta actividad productiva a quienes han hecho la actividad de recuperación de residuos sólidos y no han sido recompensados por la misma, sino que son grupos de personas víctimas de estereotipos y de la pobreza.

Planteó entonces la Corte que la superación de la pobreza en la que se encuentran estos grupos marginados requería, no la entrega de alimentos o la generación de empleos, pues la dos resultaban temporales y excluían una real inclusión social, así como el reconocimiento social que a este grupo debe la sociedad por el importante aporte que han estado haciendo al buen estado del medio ambiente. En esta oportunidad, la Corte consideró que la medida idónea para lograr la igualdad sustantiva, y la consecuente superación de la pobreza, era la transformación de las formas de contratación del Estado, es decir, la transformación institucional del mismo.Recordemos que en la primera sentencia que resolvió el caso de la licitación pública para la prestación del servicio de aseo en Bogotá en el año 2003, se exhortó al Consejo de Bogotá para que el estatuto de contratación administrativa siempre incluyera medidas afirmativas a favor de grupos discriminados, que les permitiera participar en el mismo con la posibilidad de continuar desarrollando su actividad, y además fortalecerse a sí mismos en su proceso organizativo. Piénsese en las mujeres pobres de los barrios marginados de las ciudades, que son hábiles en distintas actividades productivas, como diría una autora colombiana. La mitad de las ciudades han sido construidas con empanadas, haciendo alusión a las madres "cabeza de familia" que han educado y alimentado a sus hijos, buena parte de la mano de obra de estas ciudades tienen base en la elaboración de este alimento. Si estas mujeres fuesen beneficiaras de medidas afirmativas, dirigidas no a emplearlas, sino a que ellas pudiesen continuar y fortalecer el desarrollo de su actividad, así como sus procesos organizativos, por ejemplo, en la participación de las licitaciones para los comedores comunitarios de

\footnotetext{
${ }^{25}$ Para Joaquín Flores los derechos humanos no se pueden explicar por los derechos humanos, por tanto los derechos humanos no son las normas jurídicas, ese es el derecho de los derechos humanos. Los derechos humanos son realmente las luchas sociales para acceder a bienes y servicios, que posteriormente y no necesariamente, se juridifican.
} 


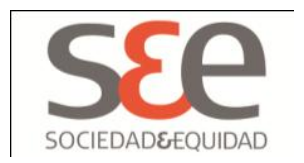

la ciudad de Bogotá, la reducción del monopolio que hoy existe sobre los mismos sería un hecho, y entonces, el camino a la reducción de la pobreza también. En el contexto de las sentencias de la Corte, resulta valioso entender la pobreza no sólo como la carencia de los bienes de los derechos sociales, sino como la carencia de reconocimiento social de la actividad que desarrollan grupos marginados. Esta carencia también alimenta la pobreza. Es importante que en estas sentencias se haga un cuidadoso y abundante relato sobre la importancia social y ambiental de la labor del reciclaje, y de cómo, paradójicamente, la sociedad desprecia a estas personas, ignorando los beneficios que para toda la colectividad tiene la selección y aprovechamiento de los residuos sólidos.

\section{Conclusiones}

La línea jurisprudencial sobre el tratamiento del lugar y derechos de los recicladores, significa para el derecho y para las políticas públicas, la ampliación del espectro de interpretación jurídica y de interpretación de la pobreza, dado que haciendo un ejercicio mas bien ajeno a los operadores jurídicos, establece una relación de mutua fertilización con producciones conceptuales de otras disciplinas para complejizar y profundizar la cuestión de aplicación del derecho, más allá del debate técnico-legal. Se vale de resultados de investigación sobre la situación de los recicladores en América Latina, así como de los saberes y la reiterada subvaloración de su trabajo, pese al impacto de bienestar que producen, para reiterar que los recicladores no deben ser excluidos del "negocio del reciclaje". Es decir, la cuestión de la pobreza no se resuelve en la generación de empleo, sino en la posibilidad de que los sectores tradicionalmente excluidos, sean valorados en sus saberes e incluidos, no como trabajadores, al proceso productivo, con la consecuencia favorable de reducir la concentración de la riqueza y el monopolio, así como el mayor control social de la actividad económica.

El quiebre estructural al modelo de exclusión y desigualdad que significan estas sentencias producidas por la Corte en este asunto, se evidencia en el incumplimiento de las mismas por parte de las autoridades públicas y de los autos adicionales que ha proferido el Alto Tribunal, exigiendo su cumplimiento. El desconocimiento y falta de visibilización de los textos de estas sentencias y su alcance hace que no sea un punto de apoyo de los movimientos sociales.

La importancia de estas sentencias radica entonces en que, no sólo dictan órdenes dirigidas a asegurar el acceso a ciertos bienes, sino que dictan órdenes encaminadas a transformar la estructura y dinámica de las instituciones sociales que buscaban perpetuar el monopolio por parte de los más fuertes en la explotación de un sector de mercado. Por supuesto, esto no significa la transformación del modelo hegemónico de desarrollo, como lo es el proyecto 


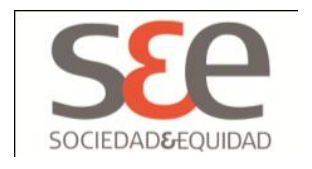

Boliviano del Buen-Vivir. No obstante, dentro de las mismas reglas del modelo económico que dirige actualmente el país, sí constituye un punto de inflexión que merece atención y análisis.

Finalmente, el estudio de la pobreza en escenarios jurídicos en los que participan ciudadanos excluidos como los recicladores, resulta muy saludable, porque estas personas experimentan el proceso judicial como un proceso político, en términos de Habermas, que reafirma su condición ciudadana y de sujeto de derechos, que estimula la interpretación de la pobreza más allá de una etiqueta que minimiza y hace pasiva a las personas, sino que la pobreza moviliza y, por tanto, integra por el canal del derecho de los jueces a ciudadanos y ciudadanas.

\section{Referencias Bibliográficas}

Corte Constitucional Colombiana (2003). Sentencia de Tutela T-724 de 2003. Disponible en internet en http://www.corteconstitucional.gov.co/relatoria/2003/T-724-03.htm

Corte Constitucional Colombiana (2009). Sentencia de Tutela T-291 de 2009. Disponible en http://www.corteconstitucional.gov.co/relatoria/2009/T-29109.htm

Corte Constitucional Colombiana (2010). Sentencia. Auto 268 de 2010. Disponible en http://www.corteconstitucional.gov.co/RELATORIA/Autos/2010/A268-10.htm

Corte Constitucional Colombiana (2012). Sentencia de Tutela T-387 de 2012. http://www.corteconstitucional.gov.co/relatoria/2012/T-387-12.htm

Flores, J. (2008). La reinvención de los derechos humanos. Sevilla: Editorial Atrapasueños.

Gómez-Correa, J. et al. (2010). Condiciones de trabajo y salud de los recicladores urbanos de Medellín (Colombia). Visible en. http://www.scsmt.cat/Upload/Documents/1/4/148.pdf (12 de julio de 2010).

Habermas, J. (2008). Facticidad y Validez, Sobre el derecho y el Estado Democrático de derecho en términos de teoría del discurso. Editorial Trotta. 


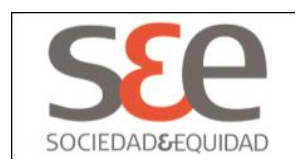

Pogge, Th. (2005). La pobreza en el mundo y los derechos humanos. Barcelona: Ediciones Paidós Ibérica S.A.

WIEGO. (2010). Mujeres en el Empleo Informal: Globalizando y Organizando. Enfocándonos en las Trabajadores Informales: Recicladoras de Basuras, visible en: http://www.wiego.org/WIEGO_En_Espanol/publicaciones/FactSheet-Rec-

Spanish.pdf. (12 de julio de 2010). 